Perspectivas - Portuguese Journal of Political Science and International Relations, N. ${ }^{\circ}$ 9, December 2012, 31-52 (c) NICPRI 2012

\title{
The Us in Justice. \\ Liberal criteria for exclusion and inclusion
}

Mario Ivan Juárez

Universidad Iberoamericana, Mexico City 
ABSTRACT:

The current debate

between national and cosmopolitan liberalism has reached a dead-

lock because of the importance they both award to culture in the realm of justice. This paper analyzes both proposals considering only the extent to which they achieve liberal objectives. On the one hand, cosmopolitanism reveals to be illiberal: Sen argues that the only way to warrant plurality is through an external eye in order to avoid dangerous localisms, which cancels cosmopolitanism's proposal as it is based on a unique metaphysical conception of the human being. On the other hand, nationa liberalism may occlude justice as fairness if the cultural and essentialist identity that shapes the state creates hurdles for distributing wealth within the national society: albeit nationalism has largely been efficient as the basis for fairness, with the advent of free-trade economy, the nationstate has lost the means to control its people's future.
"Thus, love of a country

Begins as attachment to our own field of action And comes to find that action of little importance Though never indifferent."

T.S. Eliot, "Little Gidding", Four quartets

\section{Introduction}

If Pierre Manent is right, the modern liberal state was born as a solution to the political tension between universal duties (religious and moral) and local obligations (stability requirements) at the end of Middle Age. ${ }^{1}$

First, Thomas Hobbes structured the local underpinnings on which the nationstate would establish. He argued for an absolute monarchy that solved the political dichotomy by centering the power on an unquestioned local sovereign charged of maintaining political stability disregarding any universal consideration. Challenging this position, John Locke censured Leviathan's attempt to impose a local morality on his subjects without considering their universal nature. To counterbalance Hobbes's absolute monarchy, Locke outlined the common nature of mankind: every individual is born free and equal. He stressed liberty, as a universal characteristic of humans, so as to limit Leviathan's intensions to impose its local undisputed puissance. For the author of Two Treatises of Civil Government, a local authority was merely an instrument to compensate one serious problem of human nature: the lack of impartiality that triggers the state of war. For remedying this natural issue, Locke proposed an impartial local executive power, which would apply local law for guaranteeing impartiality, on the condition that it accommodates to human's free universal nature. From his perspective, this was the only manner to establish peace in the long run. In this sense, from its origins, liberal theory favors universal human nature over local requirements.

Nevertheless, in the $19^{\text {th }}$ century, liberal theory was under theoretical attack. Socialism demonstrated that liberal freedom and equality was nothing but an abstract fiction. As a matter of fact, in Locke's liberalism, God is the guarantor of human equality: all individuals are equal before God. However, for Marxists, this postulate was simply specious. In order to make them real, equality and liberty must be material and not only formal. From their perspective, an international socialist state was the only form to establish actual freedom and equality among individuals. To answer this battering, John Stuart Mill covered Locke's theoretical 
gap: a liberal government was only possible within national frontiers, since common local culture guarantees equality among its people, beyond families, political or socio-economical allegiances. ${ }^{2}$ Mill provided the spatial framework (nation-state) for a universal politics (liberalism). He outlined local belonging as a tool for making the universal possible; in this way, he propitiated the political tension between the local and the universal... at least for a while.

Henceforth, nation-state gained political force and social acceptance until it prevailed over both conservative imperialism and socialist internationalism as the legitimate form of the state. However, liberal theory had a more convoluted story than nationalism. In the earlier $20^{\text {th }}$ century, it lost force against both utilitarian welfarism and soviet socialism. It was not until 1971 that liberalism was reborn through John Rawls's justice as fairness. His theory overcame at the same time welfarist and Marxist criticism by a restatement of liberal foundations. Through the original position's elegant mechanism, Rawls demonstrated that the neutrality of the two principles of justice make possible to shape a society compound of free and equal persons.

And yet, Rawls was obliged to take sides regarding the tension between local politics or universal morality. In what some thinkers deem a conservative reflex, he decided to continue with Mill's heritage: he refused to widen the scope of a liberal state and contented to reestablish the bridge between a liberal government and its nationstate. Following Mill, a local culture that produces equality among its members was the condition of possibility for the realization of political liberalism.

Those gainsaying Rawls on the role of the nation-state for liberal theory, the cosmopolitan liberals, essay to shape a new liberal proposal that surpasses the derided fiction of the nation in the name of true justice for every human being. They argue that an actual justice as fairness depends on the institution of universal rights that every individual is entitled to own, inasmuch liberal rights are not fettered in its essence to any local basis. In response to the cosmopolitan perspective, Rawls defended his position stating that common sympathies are the preconditions for justice as fairness, since, in addition to equality, they create the sentiment of sovereignty and autonomy.

The political tension between the universal and the local was then reopened. In effect, Rawls's position left some sort of cultural gap: henceforth, those who want to reinforce or censure his position are required to prove the importance of cultural belonging for the individuals in a liberal society. However, since the
This paper holds the hypothesis that it is not cultural sympathies that allow voluntary cooperation within the state, but it is the possibility of justice that creates common sympathies within the population. Therefore, beyond any cultural considerations, a liberal state must be defined only by the extent to which it fulfills the ethical, material and spatial requirements of justice as fairness. Area: Political Theory

KEYWORDS: Liberalism, Transnational justice, NationState, Cosmopolitanism, Justice as fairness. 
concept of culture is significantly nebulous, this debate remains dead-locked: on the one hand, national liberals extol the virtues of a liberal state grounded on cultural considerations (such as community, feeling of participation and political sovereignty); on the other hand, cosmopolitan liberals argue for the necessity of a global liberal justice (given that a true political system for free an equal people does not rely on any kind of cultural barriers).

As a matter of fact, John Stuart Mill's cultural solution has revealed itself across the centuries as a mere temporary answer. In the late $19^{\text {th }}$ century, few intellectuals doubted of the actual existence of nations; hence, they were able to furnish consensual criteria to determinate the limits of a liberal government. Nowadays, nations, as homogenous cultural entities, reveal to be fictional constructions that are simply irrelevant to fix the legitimate scope of a liberal state (cf. Hobsbawm, 1983). In this sense, for some cosmopolitans, culture is just a contingency that needs to be surpassed in the name of justice.

From this work's perspective, the reason why the debate between cosmopolitan and national liberals has not led to a clear conclusion is their exclusive focus on an erroneous question: must a liberal state accommodate to cultural criteria? This paper argues to leave cultural consideration aside and to assess which one between cosmopolitan or national liberalism is better equipped to deal with liberal objectives. From this perspective, this paper asks the following queries: what is the framework in which a liberal state can efficiently achieve its goals of equality and liberty for all its citizens? A cosmopolitan liberal state is suitable to carry out liberals' universal agenda? Does a liberal nation-state fulfill more efficiently liberal objectives through a local union? Furthermore, what are the requirements that any kind of state must satisfy so as to efficiently reach liberal goals? Are they simple ethical requirements? If so, in which measure the material requirements of liberalism matter?

Regarding these enquiries, this paper's main hypothesis is that a liberal state is more efficient in the measure in which it satisfies requirements of justice beyond local or universal considerations. This paper stresses that there must be a third way between cosmopolitan and national liberalism that provides a sound and long-term solution for the political tensions between the local and the universal within liberal theory.

In order to sketch its argument, this paper shall compose three main sections. The first section deals with the case for liberal exclusion against cosmopolitanism. 
The second part demonstrates that the national criteria is insufficient for achieve fairness. And the last section sketches the possible groundwork for elaborating liberal criteria for inclusion and exclusion.

\section{The liberal case for exclusion against cosmopolitanism}

It is undeniable that, at its core, liberalism contains a cosmopolitan seed. As a theory of political legitimacy based only on individual consent, it is against any kind of essential division among human beings. And yet, would this mean that, in order to achieve its objectives, liberalism must be cosmopolitan? Is liberal theory bound to cosmopolitanism?

\section{The cosmopolitan case against the nation-state}

It is crucial to identify what it is about exclusion that immediately triggers liberal allergy?

Cosmopolitan theorists see in the concept of nation a potentially dangerous illiberal construction, because it relies on essentialist considerations about its people's identity for excluding individuals from the state. Nonetheless, J.S. Mill argued that the nation-state was the natural space for a representative liberal government: the cultural common sympathies shared by all citizens make them equal beyond their race, family or socio-economic class. This means that nations shape the criteria for exclusion, but they are also the engines for inclusion. This shared cultural sentiment is the element that, mixed with democratic procedures, guarantees that the nation-state shall treat every citizen as a free and equal person. In this framework, the nation-state has a main task: pledging the continuity of people's traditions, beliefs and customs, through which the citizens create an idea of themselves (of who are "us"), guaranteeing that a representative government is possible; in other words, it must assure that the cultural "us" is able to govern itself through democratic institutions. From this perspective, the nation-state is the key element of political sovereignty.

And yet, throughout the $20^{\text {th }}$ century, liberals realized the two faces of nations: the bright one that achieves liberal objectives (equality, freedom and political autonomy); and the dark face that segregates the different, spreads intolerance and is always willing to annihilate the "other". For liberals, the problem is pristine: nations' pith spreads the idea of an essential "us" constantly threatened by the ex- 
istence of the "others" ${ }^{3}$. In this sense, one of the central problems of liberal theory is the nation as a potential cause of an intolerant and bellicose society. And yet, some liberals argued that it is possible to overcome nations thanks to a common rational nature. Brian Barry, for instance, stated that humans are not doomed to obey different cultural laws, given that human nature is rational, changing and adaptive. ${ }^{4}$ Therefore, if global laws reveal to be necessary for human justice, individuals could surpass national allegiances in order to gain actual justice. The cosmopolitan project sustains then that a true liberal state does not impose any essential identity to its people, because no idea of "us" is politically relevant.

\section{The gist of cosmopolitanism: radical inclusion}

This paper is generous with the cosmopolitan perspective and accepts its premises integrally. Let's forget the empirical argument that highlights that a global state is currently impossible. Let's suppose that such a state does exist and that it applies the two principles of justice to the global level. Now, let's enquire if a cosmopolitan state actually achieves the goals of a liberal theory. Does a cosmopolitan global state provide the structure for a plural society?

For cosmopolitan theorists, the answer is clear: cultural pluralism is a precondition for cosmopolitanism. In fact, the idea of pluralism is at its core given that its theoretical basis comes from the inclusionary seed of Rawls's justice as fairness. There are indeed two main characteristics of this theory that make it suitable for a pluralist society of any size: the neutrality of its principles and the impartiality of the overlapping consensus.

Since it is the element that differentiates political from comprehensive liberalism, cultural neutrality is cardinal for Rawls's proposal: it is an outcome of the fair procedure of deliberation in the famous original position. Comprehensive views are absent altogether from the original contract, because, behind the veil of ignorance, contractors are not able to take sides in favour of their particular conception of good. The principles of justice inherit the neutral characteristic of the assessment, which makes possible an overlapping consensus. ${ }^{5}$ Owing to their neutral nature, everyone is able to adopt the two principles of justice by renouncing the political force of their comprehensive doctrine. The overlapping consensus splits personal beliefs in two: on the one hand, the agent sustains a reasonable comprehensive doctrine; on the other, the agent embraces the principles of justice as his/her exclusively political relationship. As its principles guarantee 
a reasonable pluralism, Rawls conceives his liberalism as political rather than comprehensive and metaphysical ${ }^{6}$.

Contemporary cosmopolitanism results from a radicalisation of the inclusionary device of Rawls's theory. Thomas Pogge shaped its basis from a simple inference: if Rawls's principles actually institute justice for a plural society, why are they legitimately limited to the nation, as a cultural scope? If this is a theory of justice that is likely to include every single cultural perspective, thus it must be used to delineate the guidelines for global justice given that divisions between nations are merely cultural, i.e. fictional. Pogge has only to surpass one hurdle: justice as fairness is formulated for a well-ordered society, i.e. a society in which "the public conception of justice offers a point of view mutually recognized" (Rawls, 2001; 3.1)

In order to extend the principles of justice to the global level, Pogge needs to demonstrate "the importance and possibility to work for a well-ordered international society, at least in the sense of a shared kernel of political morality" (Pogge, 1989; p. 216). He inverses Rawls's argument: while the latter holds that justice is only possible within a well-ordered society, the German philosopher states that a plural society, composing reasonable cultures, should agree to share a political morality. This means that, if nations acknowledge that their cultural differences are not essential, a well-ordered global society, based on an international pluralism and on a common political morality, would be possible.

For cosmopolitans, the shared kernel of political morality takes the form of human rights. They transcend national and cultural divergences and establish a global justice through local governments. To sum up, if all nation-states embraced human rights, a plural global society would be the framework of cosmopolitan justice.

\section{The cosmopolitan argument against itself}

Even though nations were reasonable, and hence, global justice was indeed possible, would this mean that the resulting global society is actually plural? Isn't there something outlandish about a pluralism based on a single kernel of moral beliefs?

Amartya Sen questions that a global society reunited through the two principles of justice is plural. In his Idea of Justice, he wonders whether pluralism is possible within any contractual society. He asserts that the two principles of justice are not culturally neutral given that the deliberation in the original position is 
not without local and "parochial" influences. According to Sen's argument, when Rawls closed the deliberative framework, he did not elaborate any guarantees that the assessment will not be influenced by the culture of the group as a whole The contractors in the original position discuss the distribution of rights, income, wealth, and so on; nonetheless, as the national group is defined by cultural criteria in the first place, their particular cultural characteristics shall not be deemed as an issue to be discussed: the members are blind to their cultural traits. The principles of justice will be then unconsciously biased by parochial ideas given that the members are not aware of their shared cultural kernel.

As a matter of fact, Sen is attacking Rawls's primary objective: the neutrality of the principles of justice. The Economy Nobel Prize argues that the principles of justice are neutral only for those who deliberate on the original contract, yet they are actually partial for those outside the decisional group in space and time. Salvaging Adam Smith's moral vocabulary, Sen calls this feature "the procedural parochialism" of contractualism. In this sense, Rawls's liberalism fails to construct principles for a plural society because he established no guarantees against local considerations.

Nevertheless, let's concede one final word to cosmopolitans. Pogge may interrogate Sen: if the decisional group was a cosmopolitan group and the principles of justice incorporate the common points of every culture in the world, what would then be the parochialism there? In fact, this is what cosmopolitanism would mean by a "common kernel of political morality": discover a common moral that goes beyond national differences. Pogge would argue that, rather than attacking it, Sen is bolstering cosmopolitans' argument: justice as fairness, limited to a national group, produces parochial principles; ergo, the only way for eschewing parochialism would be to postulate a global original position that abolishes nations in the name of human kind. "I see why your argument discredits Rawls's theory, Amartya; yet, after your sound demonstration of parochialism, my perspective was only reinforced", Pogge would respond.

This certainly would be a skilful cosmopolitan strategy, still it seems that Sen foreknew it. The German philosopher would only see one part of it, the spatial parochialism, but he would be disregarding entirely its second part: parochialism through time.

If procedural parochialism would be only a matter of space (of different cultures sharing the same temporal context), Pogge would be right indeed and human 
rights should be embraced as a sort of cosmopolitan parochialism. Nevertheless, let's admit that a cosmopolitan original position produces global principles of justice in the form of human rights that we, humanity in the $21^{\text {st }}$ century, consider culturally neutral; yet, certainly that does not mean that future generations will continue to deem them as such. If human rights are considered to be neutral and hence suitable to every past, current and future culture, it is equivalent to affirm that we have arrived to the end of history, that no improvement can be done to our current political and moral conceptions. Postulating human rights as a timeless kernel of political morality leads to make them essential, ontological, and, thus, metaphysical principles. The idea of a political liberalism would then be destroyed by a cosmopolitan comprehensive liberalism that would impose its moral views on human nature to people disagreeing with them not only from other cultures, but also from times to come.

Postulating human rights as timeless belies Rawls's attempt to create principles of justice for a pluralist society through a purely political consideration detached from any comprehensive view. ${ }^{7}$ As a matter of fact, human rights, when applied universally, impose a metaphysical concept of the person, leading to two different scenarios: in terms of space, the imposition of comprehensive ideas is likely to trigger political conflicts; in terms of time, a metaphysical imposition inhibits the innovative thinking of future generations.

That is how Sen breaks the illusion of a global plural society gathered by a common kernel of political morality: if a plural global society is a precondition for cosmopolitan liberal justice, and if pluralism is cancelled by the sole fact of a cosmopolitan justice, then a cosmopolitan liberal justice is specious. From this perspective, cosmopolitan liberalism betrays Rawls's attempt to develop a liberal conception free from metaphysical considerations.

\section{The insufficiency of the national criteria for political fairness}

The first outcomes of the contemporary tension between universal and local liberalism are salient: universal liberalism is in fact not political but metaphysical Losing its Rawlsian basis, the cosmopolitan project appears as illiberal. Therefore, the only political liberalism possible is local. And yet, does this mean that local liberalism is unavoidably national? Does liberal nationalism present the most efficient path to reach liberal objectives? 


\section{In defense of liberal nationalism}

The contradictions of an utterly inclusive liberalism bring to light the virtues of exclusion. As a matter of fact, due to its exclusionary criteria, national liberalism can solve two of the main problems of cosmopolitanism: shaping the framework for a plural society and guaranteeing equality among the members of the nationstate.

Thanks to its distinction between a cultural "us" and an outside "them", national liberalism is likely to amend the possible parochialism of justice as fairness. According to Sen, in order to guarantee that parochial reasoning does not influence the decision of the members within Rawls's original position, the assessment of justice must be open to an outside spectator that, from a unbiased gaze, reveals the cultural axioms that remain hidden to the contractors.

Sen updates Smith's impartial spectator and transposes it to a social level so as to shun parochialism of the contractual theory. In Sen's view, a true impartial assessment of the principles of justice would proceed as follows: the members of the decisional group carry out an assessment influenced unconsciously by their local traditions; next, an outside gaze unveils what remains hidden in the group's principles of justice; and, finally, recognizing their unobserved partiality, the group is capable of reassessing their principles of justice according to its local traditions and interests. A truly impartial procedure shall be then dynamic within the group (as Rawls postulates) and outside the group (as Sen underlines).

The impartiality deficit of Rawls's theory will be only solved by a virtuous exclusion and, what Sen calls, an open impartiality: in order to be plural, a society requires the glance of impartial spectators from abroad that unveils the unconsciously cultural determinations of the group. In this sense, national liberalism is not, as the cosmopolitans believe, doomed to its illiberal potential; on the contrary, through the open impartiality procedure, national liberalism achieves the pluralistic goals of liberals.

Moreover, national liberalism structures equality among national compatriots. This characteristic is cardinal for Rawlsian liberalism, since his principles of justice are conceived for a society of free and equal persons. Cosmopolitanism recovers the idea of equality as a natural feature of mankind; i.e., for them, equality is metaphysical, hence it goes beyond any subjective consideration; this is why the only relevant community for cosmopolitans is human community: the only "us" 
is a metaphysical human "us". This imposition is fundamentally illiberal since it imposes a comprehensive version of what it is to be a human being.

On the contrary, national liberals propose a sort of equality that depends only on subjective perception and personal agreement, hence an equality that is not based on metaphysical concepts. A national culture, according to Mill, creates the framework for equality: an individual perceives himself as an equal to those who share his/her way of life, habits, mores, in one word, his/her culture. Barry is certainly right when he affirms that human nature is adaptive, changeable and rational; notwithstanding, if person A1 considers to be radically discrete to person $\mathrm{B}$, but not to person $\mathrm{A} 2$, and, therefore, wants to engage with the latter in an special kind of relationship that involves sacrifices, such as justice; thus, there is no legitimate liberal method for compelling person A1 to concur with B's requirements of justice. Perhaps this is why Burke realized that there are no human beings, but only French people, Russian people, British people, and so on.

As a matter of fact, justice implies a very particular kind of relationship. The individuals involved in such a relationship share a distributional sphere that presupposes sacrifices and an imposition of collective laws, engendering special duties among them (cf. R. Miller; 2009; p.10). For J.S. Mill, because they share a common cultural belonging, compatriots are willing to pay the special sacrifices involved in a relationship of justice so as to reach social fairness among their national group. In this sense, David Miller's illuminating sentence casts the virtues of national liberalism: "only a national distributive mechanism can guarantee fairness; and this requires ideological support at the same level. [...] The obligations of justice we are invoking extend in scope only as far as the group which forms the focus of identity" (D. Miller, 1989; p.237). In this sense, in order to achieve fairness, justice might be done only by and for those who constitute a national "us".

\section{An essential "us" against fairness}

It is cardinal to remember that, for Rawls, the primary subject of political justice is the basic structure, which is "the way in which the main political and social institutions of society fit together into one system of social cooperation and the way they assign basic rights and duties and regulate the division of advantages that arises from social cooperation over time" (Rawls, 2001; 4.1). It is evident that the concept is void of any substantial criteria for exclusion. Yet, national liberals state that a cultural background should be used to determine the scope 
of the basic structure; hence, for them, the nation is the natural space for justice as fairness. In so doing, they are imposing another metaphysical idea of the self that may come into conflict with actual requirements of justice.

Indeed, the concept of nation is mainly essentialist, thus comprehensive and metaphysical. The French anthropologist, Jean-Loup Amselle argues that, from the nationalist perspective, the state is to be found for protection of a society's cultural uniqueness; which means that the institutions are built to shield a people's culture from outside influences so as to stand good for its survival. In other words, the nation-state presupposes that national culture is pure, homogenous and immutable, and must remain as such. In this sense, national liberalism ossifies the basic structure under unvarying essentialist parameters. And yet, does this frozen framework alter possibilities to reach liberal fairness?

This paper holds that, albeit the basic structure may once have coincided with the national scope, a global free trade economy has changed its frame, which goes beyond national borders nowadays. Therefore, currently national liberalism falls short of justice as fairness.

In this sense, cosmopolitan liberals are correct: there is in fact a tension between the mechanisms of global economy and nation-states as the only device for attaining fairness. The nation-state is no more able to establish fairness among its members given that a free-market trans-national economy has undermined its sovereignty, enormously reducing their possibilities for distributing the advantages of social cooperation within its population. Indeed, if the imperatives of global economy proclaim national policies, in which sense are nation-states sovereign?

This paper asserts that this is a global phenomenon; nonetheless, it is more evident in certain regions of the world such as Europe, where the economic crisis has forced the poorer nation-states to undertake economic measures designed by the richest members, while the latter are forced to save the economies in danger so as to shun a regional and global economic collapse. For facing the economic crisis, national European governments demand major sacrifices to their citizens without their due rewards: fairness. The citizens of the nations with financial issues, such as Greece, Portugal or Spain, have to adjust to German demands for reducing expenses; however, the real tragedy is that, if the Spanish, Greek or Portuguese governments refuse to implement austerity policies or if the German government denies to support emaciated economies, the financial collapse shall be catastrophic not only for Spaniards or Greek people, but for all Europe. This 
means that citizens have no control over their future and the nation-states are no more sovereign, but they have to adjust to requirements of the economy. Hence, individuals in such nations perceive their political regimes as fundamentally illiberal and undemocratic since they do not respond to their will, but to the economic requirements of stability. In fact, even if European people share an economical context, they do not share a trans-national government that can translate their common will into just policies; instead, as European trans-national institutions respond only to the interests of the nation-states, they assure a relative equality among the latter, but not among their citizens.

Thus, by ossifying the basic structure, national liberalism may in fact occlude fairness in the case that economic requirements go beyond national frontiers. In this sense, national liberalism falls short of justice or, in extreme cases, it even obfuscates a political solution, dooming national population to live under states that assure an essential identity (a fundamental cultural "us") but cannot safeguard political fairness.

This paper argues that the disarticulation between the economic and the political domains provoked by the friction of a national essentialism and free trade transnational policies can only lead to powerlessness, instability and unfairness within the nation-states.

\section{Groundwork for exclusionist liberal criteria}

This paper agrees with Rawls when he suggests, in his Law of Peoples, that an idea of self-identity is a good in itself for a liberal people. ${ }^{8}$ In this sense, justice must be done only for those who accept to be "us". Still, this work argues that, if individuals face the dilemma of choosing between their national culture and justice, they are more likely to prefer justice. Paraphrasing and interpreting Richard Miller's dictum: Justice can cut deeper than common sympathies. ${ }^{9}$

In this sense, this work's proposal is closer to liberal nationalism than to cosmopolitanism, since it recognizes the need for developing criteria for exclusion in order to establish a relationship of justice only with those who accept to be "us". In other words, political liberalism is only local. However, as the national "us" is insufficient to ensure fairness, it is necessary to develop criteria for liberal exclusion that focus only on the requirements of justice.

Firstly, it is imperative to underline a tacit premise of this paper: the only universal 
right is the right to have rights. Hanna Arendt has already warned about the danger of political exclusion stating that every right depends materially on the state: if there is no static force that guarantees the respect to the rights of an individual, he/she is simply condemned to be destroyed.$^{10}$ Following Arendt's guidance, it shall be argued that every person has the right to be protected by a state to which he or she accepts belonging. Therefore, this work presupposes that exclusion from a state always goes hand in hand with inclusion into another one.

And yet, the claim of this work is that it is urgent to found a third way between a culturally grounded liberalism and a cosmopolitan liberalism that focuses only on the achievement of liberal objectives. In this sense, this paper's argument is normative: It endeavours to delineate the requirements that a state must fulfil to achieve justice as fairness; it also endeavours to elaborate a criteria to assess whether an existing state is able to ensure fairness or not. This proposal fundamentally intends to sketch a theoretical tool for analyzing and criticizing the scope of liberal possibilities of current nation-states.

\section{Rethinking the basic structure}

As Rawls reopened the friction between the local and the universal, the solution must be sought in his unfinished political liberalism. Rawls's theory should be recovered where he left it: the purely political conditions that a state must satisfy to be considered liberal. From this perspective, Pogge is right in evoking Rawls's conservative reflex: he left a gap in his theory by making political institutions depending on cultural considerations, i.e., in extra-political factors. Rawls left the definition of the scope of a liberal state uncompleted, letting the debate between cultural and cosmopolitanism open. It is certainly the duty of liberal theory to take up this gap so as to make political liberalism more consistent and robust.

However, Rawls left one main clue to surpass cultural considerations in the construction of a liberal state: the idea of a basic structure, which is the element that makes justice as fairness purely political. ${ }^{11}$ Thus, in order to achieve pluralism and fairness beyond any metaphysical consideration (cosmopolitan or national), it is imperative to recover the emphasis on the basic structure.

Yet, what does this "rough idea" of a basic structure mean? Until now, it has been taken for granted that the basic structure is the nation-state. This paper argues that this error is due to Rawls's Law of Peoples, in which he restricted the scope of justice as fairness, linking the unity of a democratic society to the common 
sympathies among its members, a la John Stuart Mill. ${ }^{12}$ Nonetheless, The Law of Peoples is definitely an outlandish work in Rawls's writings, since it was conceived as a response for the cosmopolitan liberals, notwithstanding Rawls's reticence to stress his perspective on global justice. Still, if one considers only to his writings on "domestic justice", Rawls never asserted that the basic structure was a nation-state. He was aware that the basic structure was not immutable; hence, he shunned providing criteria beyond its general definition, since its boundaries must be able to adjust to the changing social and economic circumstances. "Where we lay down a definition of the basic structure that draws sharp boundaries, not only would we go beyond what that rough idea could reasonably contain, but we would also risk wrongly prejudging what more specific or future conditions may call for, thus making justice as fairness unable to adjust to different social circumstances"(Rawls, 2001; 4.3). However, even from this succinct definition, it is possible to infer that the basic structure is the domain in which the advantages of social cooperation are distributed.

The advantages of social cooperation are the primary goods, which are divided into five categories (Rawls, 2001; 17.2):

1) Basic rights and liberties

2) Freedom of movement and labour

3) Powers and prerogatives linked to authority

4) Income and wealth

5) The social basis of self-respect

As it is evident, none of these elements include the idea of one shared culture as a precondition for its production. On the contrary, following Thomas Nagel, it is possible to stress that the distribution of these social goods currently goes beyond national boundaries, concerning especially the distribution of income and wealth:

I am related to the person who assembled my computer in the Philippines through the combination of U.S. and Philippine property, commercial and labor law, the international currency markets, the international application of patent law, and the agreements on trade overseen by the World Trade Organization. [...] Since we are both participating members of this network of institutions, this puts us in the same boat for purposes of raising issues of justice. (Nagel, 2005; p. 142) 
The former considerations lead to the conclusion that, as political liberalism's principles aim to establish justice as fairness within the basic structure, the criteria to define whether a state is liberal or not must consider only its possibilities to fairly distribute the advantages of social cooperation. In this sense, if the state is global, national, multinational, multicultural, and so on, is irrelevant. Indeed, the liberal state requires criteria to exclude in order to include, but it must be founded on its possibilities to distribute primary goods, not on any cultural or metaphysical considerations. In other words, a proper liberal state includes those who are inside the basic structure of society and excludes those who are not.

\section{Three requirements of justice}

It is important to specify what these primary goods are beyond the sometimesnebulous Rawlsian terms. In the following, this paper shall provide groundwork for identifying the elements that compose the liberal criteria for inclusion and exclusion.

The $1^{\text {st }}$ and the $5^{\text {th }}$ primary goods (rights, liberties and the social basis of self-respect) can be called the ethical requirements of justice. Nowadays, they take the generic form of human rights. It is essential that people should embrace human rights as a precondition to accept a liberal state. Furthermore, it is relevant to notice that cosmopolitan theorists consider them as a sufficient condition to adopt liberal justice; this paper states on the contrary that this is not a sufficient, but only a necessary condition for fairness. In this sense, if nation-state A and nation-state B embraces both human rights (i.e, share the $1^{\text {st }}$ and the $5^{\text {th }}$ primary goods), they certainly share a common kernel of political morality, still their citizens are not entitled to demand justice to each other because they do not share a complete basic structure.

The $4^{\text {th }}$ primary good (income and wealth) are the material or economic requirements of justice. They take the form of strong economic interdependences, free trade treaties, a common currency, or even harmonic movements of national GDPs. Notwithstanding, sharing an economic structure it is also a necessary condition, but not sufficient, to make claims of justice. In this sense, nation-state A and nation-state $\mathrm{B}$, sharing only economic institutions, are not entitled to demand justice to each other, but only to claim that trans-national economic agreements must be respected. ${ }^{13}$

The $2^{\text {nd }}$ primary good (free movement and labour) are the spatial or geographical requirements of justice. Despite the definition of this primary good requires of fur- 
ther analysis, it can be said that the distribution of the $2^{\text {nd }}$ primary good depends on a unified territory. ${ }^{14}$ The $2^{\text {nd }}$ primary good underlines the need for a liberal state to actually control its frontiers. Distributing the rights of free movement and labour is a vital element for justice as fairness since its principles are defined for a closed society. ${ }^{15}$ The boundaries of a liberal state must be determined by the possibility of controlling the movements of its population and labour within its territory. This suggests that the frontiers of a liberal state are not fixed once and for all, but that they depend on a posteriori study that assesses whether the state is able to control people's movements within its boundaries. In this sense, if nation-state A and nation-state B are territorially contiguous and the population of one state illegally migrates frequently to the other, it can be said that neither A nor B control their population movements; notwithstanding, if they only share the distribution of the $2^{\text {nd }}$ primary good, they are not entitled to demand justice neither.

Finally, these criteria ought to make no consideration about the $3^{\text {rd }}$ primary good (powers and prerogatives linked to authority). They endeavour to assess the scope in which a state must be established in order to guarantee justice are fairness; ergo, liberal criteria cannot include any consideration about an existing state, but essay to determinate to what extent a state can ensure fairness among its existing boundaries. Moreover, given that the states are currently national and that these criteria intend to assess a liberal state beyond national considerations, the $3^{\text {rd }}$ primary good must not be taken into account. For instance, a nation-state A can distribute fairly the $3^{\text {rd }}$ primary good, so as a nation-state B; however, since, within these nations, this good is only produced in order to safeguard a society's culture, it does not reveal anything about the puissance of A and B to control their requirements of fairness. Certainly, concerning this primary good, this paper is detached from Rawls's perspective, as he stresses that the basic structure also comprises political institutions. At this stage, this paper does not belie Rawls, but essay to correct him: the $3^{\text {rd }}$ primary good may only be distributed when the other four primary goods exist within a society; otherwise, it may occlude fairness, as it has been demonstrated above.

To sum up: a proper liberal state meets the ethical ( $1^{\text {st }}$ and $5^{\text {th }}$ primary goods), material ( $4^{\text {th }}$ primary good $)$ and spatial ( $2^{\text {nd }}$ primary good $)$ requirements of justice as fairness. In other words, a liberal state ought to correspond with the basic structure of society in order to ensure fairness among its members. This paper restates David Miller's dictum: a national ideological support does not guarantee 
fairness per se, but it is the requirements of justice that guarantee the survival of any idea of "us". In this sense, Rawls's justice can cut deeper than Mill's common sympathies.

An illustration should better clarify the liberal criteria for inclusion and exclusion. Let's consider the hypothetical case of nation-state A, B and C. If they all embrace human rights, but a strong economic integration exists only between A's and B's domestic economies, and if A's and B's populations are in constant movement from one state to the other, A and B are actually sharing the same basic structure. Thus, any unilateral policy of A (or B) shall result insufficient to distribute fairly the advantages of social cooperation, since its basic structure goes beyond its national puissance. The only way to guarantee justice as fairness for A's and B's citizens is to melt nation-state A and nation-state B in a new state $\mathrm{X}$ (which may then distribute the $3^{\text {rd }}$ primary good) that would actually be able to distribute the five primary goods fairly. However, as $\mathrm{C}$ only fulfils the ethical requirement, but falls short of the other two, it must be excluded from new liberal state $\mathrm{X}$.

In this case, A and B cannot be deemed liberal states by their own (ergo, they neither are sovereign nor democratic), since each one is not able to produce a fair distribution of their primary goods and to install fairness. And yet, since the only state that is liberal (thereby sovereign) in this equation is state $\mathrm{X}$, the A's and B's national monopole of the $3^{\text {rd }}$ primary good shall be transfer to $\mathrm{X}$ in order to constitute a representative government and ensure not only justice, but also democracy. Inasmuch as this work is mainly normative, it holds that, if $\mathrm{X}$ does not exist, it should be created.

This is the main theoretical proposal of this work: any state that does not fulfil these liberal criteria cannot institute fairness within its population and, hence, can be neither liberal nor fair. Therefore, it must exclude those who are an obstacle for this task, or include those without whom justice is simply not possible. Moreover, people must agree to be excluded from a state that cannot establish fairness for them, and agree to be included into a state that is capable of performing this task. In both cases, exclusion or inclusion of people must be guided exclusively by the requirements of justice. In this sense, this paper formulates a new response to the tension between the universal and the local concerning liberal theory: a universal liberalism fails to achieve pluralist goals, whereas a local liberalism should depend only on the requirements of justice despite any cultural or metaphysical consideration. 


\section{Conclusion: a liberal "us"}

If this paper is right, the current global economic context reveals that modern liberal state was only a palliative solution for the political tension between the universal and the local. The nation-state was an ephemeral response to a wider problem, symbolized nowadays by the controversy between cosmopolitan and national liberals. On the one hand, cosmopolitan liberals refuse to develop a political vocabulary that distinguishes "us" from "them", given that, in their view, the only "us" that is politically relevant is provided by the natural unity of mankind; any other human division is an illusion. On the other hand, national liberals maintain that cultural sentiments generate feelings of community making voluntary cooperation possible among equal individuals. Indeed, they recognize political liberalism's need for formulating a normative framework for differentiating "us" from "them": those who share a common national culture are "us", those who do not, are "them".

Both cosmopolitans and nationalist liberals fail to create a state that is efficient for reaching liberal goals. On the one hand, because of their metaphysical concept of the individual, cosmopolitans erase the idea of "them" forgetting that justice must be done only for those who accept to be "us". On the other hand, nationalist liberals are committed to an essential and cultural "us", neglecting to consider the distributional structure of primary goods and the material requirements of justice. In this sense, cosmopolitan and national liberalism occlude liberal objectives.

In contrast, a proper liberal state focuses only on the requirement of justice to define the distinction between "us" and "them". A liberal state neither depends on a universal conception of the person, nor creates essential obstacles for establishing fairness within the actual basic structure of society. To clearly answer our question, people must agree to be included in a liberal state only if it fulfils the requirements of justice: if it embraces human rights, has the control to distribute the wealth created by social cooperation, and can guarantee freedom of movement within its territory.

Within this theoretical framework, it is possible to better understand the European current situation. European member states are not able unilaterally to ensure fairness on their national territory, since there is a sound economic integration among them. In other words, these nation-states are neither liberal nor fair on their own; ergo, political national authority is experienced as an imposition by the citizenry. Still, analyzing the situation through the lens of liberal criteria for 
inclusion and exclusion, it is possible to be more optimistic. All member states embrace human rights, and, thanks to the Schengen treaty, they can control their population within the frontiers of the Schengen space. Therefore, It can be inferred that the European Union shares already the three requirements of justice; the only element that is left is the $3^{\text {rd }}$ primary good. This paper states that, in order to re-establish fairness among European citizenry it is necessary that the their nation-states renounce their illusionary sovereignty in order to gain sovereignty at European level, and, hence, recover the puissance to organize social cooperation through fair arrangements. It is the only path for Europe to retrieve liberal justice, fairness and stability.

Thomas Nagel finished his paper on global justice with the following words: "We are unlikely to see the spread of global justice in the long run unless we first create supranational institutions that do not aim at justice but that pursue common interests and reflect inequalities of bargaining power among existing states" (Nagel, 2005; p.146). It can be said that Europe has already reached this point: European institutions leaded by national interests reflects inequalities among the member states. Therefore, it is certainly time to restructure these transnational institutions in order to guarantee fairness for the European people not for European nation-states.

In short, this paper argues that the only "us" that is politically relevant for liberalism is the us in justice.

\section{References}

Arendt, Hannah. 2004. The Origins of Totalitarianism. New York: Schocken Books. BARry, Brian. 2002. Culture and Equality. Cambridge, MA: Harvard University Press.

Hobsbawm, Eric. 1983. "Inventing Traditions", in The Invention of the Tradition, ed. Eric Hobsbawm and Terence Ranger. 1983. Cambridge, UK: Cambridge University Press.

MiLL, John Stuart. 2009. Considerations on Representative Government, Paris: Gallimard.

Manent, Pierre. 2009. Histoire Intellectuelle du Libéralisme, Paris: Hachette.

Miller, David. 1989. Market, State, Community. Oxford: Clarendon Press.

Miller, Richard. 2007. "Unlearning American Patriotism". Theory and Research in Education 5. https://courses.cit.cornell.edu/rwm5/. (Accessed September 2012).

2011. "Rawls and Global Justice: A Dispute Over a Legacy". The Monist 94. https: //courses.cit.cornell.edu/rwm5/. (Accessed September 2012). 
NAGel, Thomas. 2005. "The Problem of Global Justice". Philosophy and Public Affairs: 133-147.

Pogge, Thomas. 1989. Realizing Rawls. London: Cornell University Press.

Rawls, John. 1972. Theory of justice. Oxford: Clarendon Press. 1999. Collected Papers. Cambridge, MA: Harvard University Press. 2005. Political Liberalism. New York: Columbia University Press. 2001. Justice as Fairness: A Restatement. Cambridge, MA: The Belknap Press of

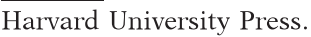
1997. The Law of People, Cambridge MA: Harvard University Press.

SEN, Amartya. 2009. The Idea of Justice. London: Allen Lane.

Smith, Adam. 2002. Theory of Moral Sentiments. Cambridge, UK: Cambridge University Press.

1 "[At the end of the Middle Age,] the political problem of Europe is the following: the non-religious, profane and laic world must be organized in a form other than the city and the empire, less 'singular' than the city, and a less 'universal' than the empire; or a form in which the universality was different from empire's universality. We now know that this political form would be the absolute or national monarchy." (Manent, 2009; p. 25)

2 "A portion of mankind may be said to constitute a Nationality, if they are united among themselves by common sympathies, which do not exist between them and any others-which make them co-operate with each other more willingly than with other people, desire to be under the same government, and desire that it should be government by themselves or a portion of themselves, exclusively. This feeling of nationality may have been generated by various causes. Sometimes it is the effect of identity of race and descent. Community of language, and community of religion, greatly contribute to it. Geographical limits are one of its causes. But the strongest of all is identity of political antecedents; the possession of a national history, and consequent community of recollections; collective pride and humiliation, pleasure and regret, connected with the same incidents in the past. None of these circumstances however are either indispensable, or necessarily sufficient by themselves." (Mill, 2009; p. 258)

3 What Vico called la boria delle nazioni.

4 "It is quite legitimate to hope that eventually a common standard of reasonableness will prevail over a certain range of ethical questions, in a way similar to that in which acknowledgement of the soundness of the physical sciences has diffused through the world." (Barry, 2001; p. 262.)

5 "As a political conception for the basic structure justice as fairness as a whole tries to provide common ground as the focus of an overlapping consensus. It also hopes to satisfy neutrality of aim in the sense that basic institutions and public policy are not to be designed to favor any particular comprehensive doctrine." (John Rawls, 2005; pp. 193-194.)

6 Cf. J. Rawls, "Justice as Fairness: Political not Metaphysical", in Rawls, 1999.

7 "This conception of justice avoids certain philosophical and metaphysical claims. Briefly, the idea is that in a constitutional democracy the public conception of justice should be, as far as possible, independent of controversial philosophical and religious doctrines." (Rawls 1999; p. 388). 
8 Cf. J. Rawls, 1997, Section 7, "The tolerance of non-liberal people".

9 In this point, this paper's argument is parallel to Richard Miller's argument about the relation between the democrative imperative and the Principle of Sympathy: "One can sum up the crucia argument as an application of a democratic imperative: if an imposed arrangement does not provide fair terms of cooperation, then those who take part in the choice of what to impose have the duty to end this subordination, even if they will lose benefits that are important in the pursuit of worthwhile goals [...]. Because it can require choices that pose a significant risk of worsening one's life, the democratic imperative can cut deeper than the Principle of Sympathy." (R. Miller, 2011).

${ }^{10}$ Cf. Hanna Arendt, 2004. Chapter 9, "The Decline of the Nation-State and the End of the Rights of Man".

11 "Justice as fairness is a political, not a general, conception of justice: it applies first to the basic structure and sees the other questions of local justice and also questions of global justice [...] as calling for separate considerations on their merits." (Rawls, 2001; 4.2).

12 "Here I think of the idea of nation as distinct from the idea of government or state, and I interpret it as referring to a pattern of cultural values of the kind describes by Mill." (Rawls, 1997; p. 25n)

13 “Contracts between sovereign states [...] are 'pure' contracts, and nothing guarantees the justice of their results. [...] The obligations they create are not and need not to be underwritten by any kind of socioeconomic justice. They are more primitive than that." (Nagel, 2005; p. 141)

14 This argument is not free from polemic. Richard Miller calls in question this requirement: "while actual modern government - perhaps all government worthy of the level - involves territorial sovereignty, this is not essential. What is essential is that the imposition have a deep impact on the lives of those who remain subjects and that there are deep costs of leaving its sphere. A framework for self-advancement imposed among a nomadic band could sustain the original position" (R. Miller 2011; p. 20). Nevertheless, this paper sustains that the $2^{\text {nd }}$ primary good implies a geographical territory.

15 "Recall that in explaining the emphasis put on the basic structure as subject, we said that we view citizens as born into society: it is there that they will lead a complete life. They enter that social world only by birth, leave it only by death." (Rawls, 2001; 16.1) 